JURNAL HUTAN LESTARI (2019)

Vol. 7 (3) : 1167 - 1174

\title{
PERILAKU MAKAN DAN JENIS PAKAN ORANGUTAN (Pongo pygmaeus) DI HUTAN DESA GURUNG MALI KECAMATAN TEMPUNAK KABUPATEN SINTANG
}

\author{
(Feeding Behavior And Food Types Of Orangutans (Pongo pygmaeus) In Forest Of Gurung Malih
} Village Tempunak Sub-district Sintang District)

\author{
Hardiyansah, Hari Prayogo, M. Sofwan. Anwari \\ Fakultas Kehutanan Universitas Tanjungpura Jl. Daya Nasional, Pontianak 78124 \\ E-mail : hardiyahsah@gmail.com
}

\begin{abstract}
The condition of orangutan habitat in ex-situ conservation areas is different from the condition of their natural habitat. These different habitat conditions will have an impact on orangutan behavior, especially food behavior and selection of feed types. This study aims to determine the feeding behavior and the food types of orangutans (Pongo pygmaeus) in the Forest Of Gurung Mali Village Tempunak Sub-district Sintang District. Observation of eating behavior is done using the focal animal sampling method. Observation of eating activities is quantitative, namely recording the time taken during orangutan eating activities. Observation of the type of feed is done by observing the remnants of discarded plants found on the forest floor and trees found as a place for orangutans looking for food sources. Based on observations of the eating behavior of each individual orangutan for the food provided shows the behavior of eating while sitting is higher than the percentage of other eating behavior. For the eating behavior that they are looking for themselves, it shows that Oscar, Digo and Putri tanjung individuals have higher hanging behavior compared to other eating behaviors. The percentage of Momo and Jojo individuals sat higher eating behavior compared to the percentage of other eating behaviors. The types of feed found in the study site were found 8 types of feed provided by the Rehabilitation center and 24 types of natural food contained in the enclosure forest.
\end{abstract}

Keywords : Feeding Behavior, Orangutan, Type of Feed.

PENDAHULUAN

Indonesia adalah satu diantara negara yang memiliki kekayaan keanekaragaman spesies primata, dimana $20 \%$ spesies primata dunia dapat ditemukan di Indonesia. Satu diantaranya dari spesies primata tersebut adalah orangutan, satu-satunya spesies kera besar yang dapat ditemukan di Asia (Supriatna dan Wahyono, 2000). Menurut Collinge (1993) dan Meijaard dkk. (2001) populasi orangutan pada jaman pleistosen sebenarnya tersebar luas di dataran Cina, Asia Tenggara hingga di Pulau Jawa. Populasi orangutan pada masa sekarang hanya terdapat di Pulau Sumatra dan Kalimantan. Jenis orangutan di kedua pulau tersebut berbeda yaitu orangutan Sumatera (Pongo abelii) dan orangutan Kalimantan (Pongo pygmaeus) (Rowe, 1996 ; Groves, 1999 ; Supriatna dan Wahyono, 2000).

Orangutan tergolong dalam ordo primata dan termasuk mamalia besar yang bersifat arboreal yaitu banyak 
menghabiskan waktunya di atas pohon. Satwa ini sangat tergantung pada pepohonan yang dimanfaatkannya untuk bergerak, sumber penghasil makanan, dan juga sebagai tempat tinggal (sarang). Orangutan umumnya ditemukan di hutan dataran rendah (dibawah $500 \mathrm{~m} \mathrm{dpl}$ ) dan bersifat frugivora, yaitu orangutan banyak mengkonsumsi buah sebagai makanan utamanya (Rowe, 1996 ; Whitten dan Compost, 1998 ; Meijaard dkk., 2001).

Hutan dataran rendah dan hutan lahan gambut menjadi lokasi tanaman berbuah dan merupakan daerah jelajah orangutan, dibandingkan hutan Dipterocarpaceae yang kering dan didominasi pohon-pohon tinggi berkayu besar. Orangutan Borneo sangat rentan dengan gangguan-gangguan di habitatnya (WWF Indonesia, 2011). Populasi Orangutan di habitatnya saat ini mengalami penurunan drastis, diperkirakan dalam kurun waktu 10 tahun terakhir populasi tersebut sudah berkurang 30- 50\% (Primack dkk., 1998). Penurunan populasi karena habitatnya telah rusak oleh penebangan liar, kebakaran hutan dan tingginya perburuan liar (Meijaard dkk., 2001).

Penyusutan dan kerusakan kawasan hutan dataran rendah yang merupakan habitat orangutan saat ini telah mencapai titik kritis. Kerusakan hutan akibat perambahan hutan menjadi perkebunan dan pemukiman, kebakaran hutan, dan maraknya perburuan liar menyebabkan populasi orangutan semakin menurun. Kondisi yang sangat memprihatinkan tersebut telah menempatkan orangutan kedalam kategori kritis atau sangat terancam punah (IUCN, 2007 dalam Departemen Kehutanan, 2007).

Kondisi ini menyebabkan orangutan berada diambang kepunahan, serta menjadi langka dan akhirnya dilindungi. Orangutan di tingkat nasional dilindungi keberadaannya oleh UU No 5 Tahun 1990 tentang Konservasi Sumber Daya Alam Hayati dan Ekosistemnya, serta PP No 7 Tahun 1999 tentang Pengawetan Flora dan Fauna Indonesia (Marpaung, 1995 ; Anonim, 1999). Di tingkat internasional orangutan adalah satwa yang termasuk dalam kategori genting IUCN dan tidak dapat diperdagangkan karena berada dalam daftar Appendix I CITES (Anonim, 1994 ; Anonim, 1998).

Penyusunan strategi konservasi orangutan sangat diperlukan untuk menjaga kelestarian populasi orangutan. Strategi pelestarian jangka panjang yang terbaik untuk mempertahankan spesies orangutan adalah perlindungan populasi dan komunitas alami di habitat alami yang dikenal dengan konservasi in-situ. Adanya aktivitas manusia yang berlebihan seperti perambahan kawasan hutan dan perburuan liar yang secara langsung mengancam keberadaan orangutan di habitat aslinya menjadikan upaya konservasi in-situ menjadi kurang efektif. Satu diantara upaya untuk mencegah kepunahan satwa langka adalah dengan memelihara individu-individu alami dalam kondisi terkendali dan di bawah pengawasan manusia yang dikenal dengan konservasi ex- 
situ. Satu diantara konservasi ex-situ untuk penyelamatan orangutan di Kalimantan Barat adalah Sintang Orang Center. Konservasi ex-situ Sintang Orangutan Center terdapat di Hutan Desa Gurung Mali, Kecamatan Tempunak, Kabupaten Sintang.

Kondisi habitat orangutan di area konservasi ex-situ berbeda dengan kondisi habitat aslinya. Perbedaan kondisi habitat ini akan berdampak terhadap perilaku orangutan terutama perilaku makan dan pemilihan jenis pakan. Penelitian ini bertujuan untuk mengetahui perilaku makan dan jenis pakan orangutan (Pongo pygmaeus) di Hutan Desa Gurung Mali Kecamatan Tempunak Kabupaten Sintang.

\section{METODE PENELITIAN}

Penelitian ini dilakukan di Pusat Rehabilitasi Sintang Orangutan Center yang berada di Hutan Desa Gurung Mali Kecamatan Tempunak Kabupaten Sintang Kalimantan Barat. Penelitian ini dilakukan selama kurang lebih 2 bulan dari bulan mei sampai juni 2016. Objek dalam penelitian adalah lima individu orangutan yang terdiri dari dua anak-anak (jantan dan betina), dua remaja (jantan dan betina) dan satu dewasa (betina). Kegiatan penelitian orangutan dilakukan mulai dari pagi jam 05:30 WIB dan berlangsung sepanjang pagi, siang dan sore hari dan berakhir ketika menjelang orangutan tidur sekitar jam 17:30 WIB.

Pengamatan perilaku makan ini menggunakan metode focal animal sampling yang dilakukan secara purposive dengan mengikuti individu orangutan yang diamati. Pengamatan ditujukan untuk mengamati perilaku makan orangutan selama melakukan aktivitas makan (mulai memetik sampai memasukan kedalam mulut). Pengamatan aktivitas makan bersifat kuantitatif yaitu mencatat waktu yang diperlukan selama aktivitas makan orangutan. Pengamatan jenis pakan ini dilakukan dengan cara mengamati sisa tumbuhan yang dibuang yang terdapat di lantai hutan dan pohon yang ditemukan sebagai tempat orangutan mencari sumber pakan. Sedangkan yang diamati yaitu bagian-bagian yang dimakan orangutan.

Perhitungan rata-rata waktu makan dari data yang telah disusun dalam daftar adalah sebagai berikut (Said dan Kusnandar, 1987 dalam Murzani, 2004) dengan rumus :

$\bar{X}=\frac{\sum \mathrm{Xi}}{n i}$

Dimana :

$\bar{X}=$ rata-rata lama waktu makan

$\sum \mathrm{xi}=$ jumlah waktu makan ke-i

ni = banyaknya data waktu makan ke-i

Persentase waktu setiap aktivitas makan orangutan dapat dihitung dengan menggunakan rumus Dajan (1986) dalam Murzani (2004 :) sebagai berikut :

$\mathrm{Pij}=\frac{\mathrm{Xij}}{a} \times 100 \%$

Dimana :

Pij $=$ Persentase waktu setiap aktivitas makan orangutan ke-i pada pengamatan kej.

Xij = Waktu aktivitas makan orangutan ke-i pada pengamatan ke-j.

$\mathrm{a}=$ Total waktu aktivas makan orangutan selama sehari. 


\section{HASIL DAN PEMBAHASAN}

Orangutan yang berada di Sintang Orangutan Center berjumlah 33 ekor, dimana orangutan yang ada ditempatkan pada dua tempat yang berbeda. 17 ekor ditempatkan di Sintang dalam masa karantina sedangkan 16 ekor lainnya berada di Sekolah Hutan Tembak Desa Gurung
Mali. Orangutan yang diamati berjumlah 5 ekor, adapun pertimbangan yang digunakan untuk memilih orangutan yaitu jenis kelamin, umur dan kondisi kesehatan. Orangutan tersebut yaitu Oscar, jantan anakanak, Digo betina anak-anak, Momo jantan remaja, Jojo betina remaja dan Putri tanjung betina dewasa.

Tabel 1. Data Orangutan yang Diteliti di Sintang Orangutan Center (SOC) (Data of Orangutans Studied in Sintang Orangutan Center)

\begin{tabular}{clcccc}
\hline No & $\begin{array}{c}\text { Nama } \\
\text { Orangutan }\end{array}$ & $\begin{array}{c}\text { Jenis } \\
\text { Kelamin }\end{array}$ & Umur (tahun) & Tanggal datang & Keterangan \\
\hline 1 & Oscar & Jantan & 4 (anak-anak) & 28 November 2014 & $\begin{array}{c}\text { Diambil dari peliharaan warga } \\
\text { Putussibau }\end{array}$ \\
2 & Digo & Betina & 3 (anak-anak) & 18 Mei 2014 & $\begin{array}{c}\text { Diambil dari peliharaan warga } \\
\text { Pontianak }\end{array}$ \\
3 & Momo & Jantan & 9 (remaja) & 20 Januari 2013 & $\begin{array}{c}\text { Diambil dari peliharaan warga } \\
\text { Melawi }\end{array}$ \\
4 & Jojo & Betina & 7 (remaja) & 3 Januari 2012 & $\begin{array}{c}\text { Diambil dari peliharaan warga } \\
\text { Tembak (Tempunak) }\end{array}$ \\
5 & $\begin{array}{l}\text { Putri } \\
\text { Tanjung }\end{array}$ & Betina & 12 (dewasa) & 14 Januari 2013 & $\begin{array}{c}\text { Diambil dari peliharaan warga } \\
\text { Sanggau }\end{array}$ \\
\hline
\end{tabular}

Penelitian perilaku makan dan jenis pakan orangutan dilakukan di kandang terbuka (enclosure cage) di Dusun Tembak Desa Gurung Mali Kecamatan Tempunak Kabupaten Sintang. Hutan enclousure tersebut ditumbuhi dengan berbagai macam jenis vegetasi alami yang cukup rapat dan hutan tersebut di kelilingi pagar listrik guna mencegah orangutan agar tidak keluar dari zona enclosure. Luas hutan enclosure sekitar 2 ha, tinggi dari pagar listrik \pm 4 meter. Kegiatan dilakukan mulai pukul 05:30 WIB pada saat orangutan belum bangun tidur dan masih berada dalam sarang sampai pukul 17:30 WIB. Pengamatan aktivitas harian orangutan yang diamati dikelompokan mengacu pada Maple (1980) dan Galdikas (1984). Suatu aktivitas akan dikelompokkan ke dalam aktivitas makan apabila orangutan memasukkan makanan ke dalam mulut, sebagian atau seluruhnya, kemudian menelan makanan atau sari makanan tersebut.

Berdasarkan hasil pengamatan perilaku makan orangutan yang telah dilakukan dapat dilihat bahwa setiap orangutan memiliki perilaku makan yang berbeda-beda. Beberapa perilaku orangutan pada waktu makan yaitu makan sambil duduk, bergelantungan, berdiri dan baring. Perilaku 
makan setiap individu orangutan untuk pakan yang disediakan menunjukan perilaku makan sambil duduk lebih tinggi persentasenya dibandingkan dengan persentase perilaku makan lainya. Untuk perilaku makan yang mereka cari sendiri menunjukan individu Oscar, Digo dan Putri tanjung persentase perilaku makan bergelantungan lebih tinggi dibandingkan dengan persentase perilaku makan lainnya. Sedangkan individu Momo dan Jojo persentase perilaku makan duduk lebih tinggi dibandingkan dengan persentase perilaku makan lainnya.

Tabel 2. Persentase Perlikau Makan Orangutan (Percentage of Orangutan Feeding Behavior)

\begin{tabular}{|c|c|c|c|c|c|c|}
\hline \multirow[t]{2}{*}{ No } & \multirow[t]{2}{*}{ Orangutan } & \multicolumn{5}{|c|}{$\begin{array}{c}\text { Perilaku Makan } \\
\text { Pakan yang Disediakan }\end{array}$} \\
\hline & & Duduk & Bergelantungan & Berdiri & Baring & Tota \\
\hline 1 & Oscar & $71 \%$ & $29 \%$ & 0 & 0 & $100 \%$ \\
\hline 2 & Digo & $92 \%$ & $8 \%$ & 0 & 0 & $100 \%$ \\
\hline 3 & Momo & $100 \%$ & 0 & 0 & 0 & $100 \%$ \\
\hline 4 & Jojo & $100 \%$ & 0 & 0 & 0 & $100 \%$ \\
\hline 5 & Putri Tanjung & $100 \%$ & 0 & 0 & 0 & $100 \%$ \\
\hline \multirow{2}{*}{ No } & \multirow{2}{*}{ Orangutan } & \multicolumn{5}{|c|}{ Pakan Alami } \\
\hline & & Duduk & Bergelantungan & Berdiri & Baring & Tota \\
\hline 1 & Oscar & $45 \%$ & $49 \%$ & 0 & $6 \%$ & $100 \%$ \\
\hline 2 & Digo & $26 \%$ & $69 \%$ & $5 \%$ & 0 & $100 \%$ \\
\hline 3 & Momo & $58 \%$ & $37 \%$ & $2 \%$ & $3 \%$ & $100 \%$ \\
\hline 4 & Jojo & $64 \%$ & $31 \%$ & $1 \%$ & $4 \%$ & $100 \%$ \\
\hline 5 & Putri Tanjung & $43 \%$ & $57 \%$ & 0 & 0 & $100 \%$ \\
\hline
\end{tabular}

Perilaku makan merupakan salah satu aktivitas utama perilaku harian yang mencakup waktu yang dipakai seekor orangutan untuk menggapai, mendapatkan, mengunyah dan menelan makanan pada suatu sumber pakan (Galdikas, 1986). Orangutan Tanjung Puting menggunakan waktu untuk aktivitas makan 50-60\% dari total aktivitas hariannya, karena aktivitas makan merupakan aktivitas penting dalam menggantikan energi yang hilang (Rikjsen, 1978).

Makanan berfungsi untuk kelangsungan hidup primata melakukan aktivitas bergerak dan aktivitas lainnya, juga dapat menetralisir zat-zat racun yang terkonsumsi. Demi kelangsungan hidup satwa tersebut makanan harus selalu tersedia dan apabila jumlah makanan yang tersedia kurang maka akan terjadi persaingan dalam memperebutkan makanan.

Berdasarkan hasil pengamatan pakan orangutan yang diamati secara langsung dengan menggunakan teropong binokuler dan sisa-sisa pakan yang terdapat dilokasi penelitian ditemukan 8 jenis pakan yang disediakan oleh pusat Rehabilitasi dan 24 jenis pakan alam yang terdapat pada hutan enclosure. 
Tabel 3. Jenis-jenis Pakan yang Disediakan Pusat Rehabilitasi (Types of Feed Provided by Rehabilitation Centers)

\begin{tabular}{cllc}
\hline No. & Jenis Pakan & \multicolumn{1}{c}{ Nama Latin } & Bagian yang dimakan \\
\hline 1 & Pisang & Musa paradisiaca & Buah \\
2 & Bengkoang & Pachyrhizus erosus & Umbi \\
3 & Nanas & Ananas comosus & Buah \\
4 & Ubi jalar & Ipomoea batatas $L$ & Umbi \\
5 & Pepaya & Carica papaya & Buah \\
6 & Nangka & Artocarpus heterophyllus & Buah \\
7 & Jagung & Zea mays & Sari \\
8 & Tebu & Saccharum sp. & Sagi \\
\hline
\end{tabular}

Pakan yang disediakan oleh pihak rehabilitasi adalah buah-buahan berupa pisang, nanas, papaya, nangka, jagung, umbi-umbian berupa bengkoang, ubi jalar, dan sari tebu. Jenis-jenis pakan tersebut dipilih untuk diberikan kepada orangutan karena memang disukai. Pemberian pakan Orang utan pada pagi dan sore hari akan mencari makan dari pakan alami yang tersedia di hutan enclosure.

Orangutan selain makan pakan yang disediakan, mereka juga makan pakan alami. Jenis pakan alami orangutan yang berasal dari alam disajikan pada Tabel 4. dilakukan satu kali sehari pada sore hari.

Tabel 4. Jenis-jenis Pakan yang Tidak Disediakan (alami) (Types of Feed Not Provided (natural feed))

\begin{tabular}{cllc}
\hline No. & Jenis Pakan & \multicolumn{1}{c}{ Nama Latin } & Bagian yang dimakan \\
\hline 1 & Rotan & Plectocomiopsis borneensis & Umbut \\
2 & Rumput Tajam & Sceleria sp. & Umbut \\
3 & Simpur & Dillenia sp. & Daun \\
4 & Cempedak & Artocarpus integer & Kulit, Daun, Tangkai daun \\
5 & Nibung & Oncosperma sp. & Umbut \\
6 & Bambu & Bambusa vulgaris schard & Daun \\
7 & Medang & Litsea sp. & Daun dan Buah \\
8 & Rayap & Isoptera sp. & Serangga \\
9 & Liana & liana sp. & Kulit \\
10 & Mentawak & Artocarpus anisophylius & Kulit \\
11 & Kayu Ara & Ficus gibbosa & Kulit dan daun \\
12 & Pulai & Alstonia angustifolia & Kulit \\
13 & Mahang & Macaranga spp. & Kulit \\
14 & Sirih Hutan & Piper aduncum L. & Daun \\
15 & Jamur Grigit & Schizophyllum commune & Jamur \\
16 & Kapuak & Artocarpus elasticus & Kulit dan Daun \\
17 & Belian & Eusideroxylon zwagery & Daun \\
18 & Ubah & Syzygium sp. & Daun dan Buah \\
19 & Kecombrang & Etlingera elatior & Umbut \\
20 & Kumpang & Knema laurina & Daun \\
21 & Jelutung & Dyera lowii & Daun \\
22 & Pandan Hutan & Platea latifolia & Umbut \\
23 & Meranti Merah & Shorea stenoptera & Daun \\
24 & Madu kelulut & Trigona sp. & Madu \\
\hline
\end{tabular}


Hutan enclosure merupakan hutan yang banyak ditumbuhi tumbuhan berkayu, semak, tanaman herba dan jenis tumbuhan lainnya. Kondisi ini memungkinkan orangutan mengkonsumsi berbagai jenis pakan selain yang disediakan oleh Pusat Rehabilitasi SOC. Selain pakan yang disediakan Pusat Rehabilitasi SOC orangutan juga mengkonsumsi tumbuhan yang tumbuh didalam hutan enclosure. Bagian dari jenis-jenis pakan yang dikonsumsi orangutan didalam hutan enclosure berupa daun, tangkai daun, kulit kayu, madu, buah, umbut, jamur dan serangga.

\section{Kesimpulan}

Berdasarkan hasil dan pembahasan dapat diambil beberapa kesimpulan sebagai berikut :

1. Perilaku makan orangutan yang umum dilakukan yaitu perilaku makan duduk dan perilaku makan bergelantungan.

2. Jenis pakan orangutan ada 32 jenis yang terdiri atas 8 jenis pakan yang diberikan pusat rehabilitasi (SOC), dan terdapat 24 jenis pakan yang tersedia di hutan enclosure. Bagian yang dimakan berupa buah, umbi, sari, daun, jamur, umbut, kulit kayu, tangkai daun, madu, dan serangga.

\section{Saran}

Saran yang dapat diusulkan berdasarkan dari hasil dan pembahasan penelitian ini antara lain :

1. Guna melindungi orangutan dari kepunahan diperlukan usaha-usaha untuk mempertahankan habitatnya, seperti memberikan penyuluhan kepada masyarakat agar tidak melakukan pemburuan, penebangan, dan pembukaan hutan secara besarbesaran serta merusak hutan, karena orangutan merupakan satwa yang dilindungi.

2. Sehubungan telah dilakukannya penelitian tentang perilaku makan dan jenis pakan orangutan (Pongo pygmaeus) di Hutan Desa Gurung Mali Kecamatan Tempunak Kabupaten Sintang akan lebih baik lagi apabila dilakukan penelitian lebih lanjut mengenai nilai gizi dari suatu jenis pakan orangutan tersebut.

\section{UCAPAN TERIMAKASIH}

Penulis mengucapkan banyak terima kasih kepada seluruh staf dan tenaga kerja Sintang Orangutan Center (SOC) Kabupaten Sintang, Kalimantan Barat yang telah memberikan dana serta tempat tinggal selama kegiatan penelitian.

\section{DAFTAR PUSTAKA}

Anonim.

1994.

www.wcmc.org.uk/species/animals/ categories.html, diakses pada tanggal 07-03-2016.

Anonim. 1998. Checklist of CITES Species. CITES Secretariat/World Conservation Monitoring Centre. Châtelaine-Genève.

Anonim. 1999. PP 7 Tahun 1999 Tentang Pengawetan Flora dan Fauna Indonesia. Direktorat Jenderal Perlindungan Hutan dan Konservasi 
Alam Departemen Kehutanan dan Perkebunan.

Collinge, N.E. 1993. Introduction to Primate Behavior. Kendall-Hunt Publishing Company. DubuqueIowa.

Departemen kehutanan. 2007. Strategi dan Rencana Aksi Konservasi Orangutan Indonesia 20072017. Direktorat Jenderal Perlindungan Hutan dan Konservasi Alam Departemen Kehutanan.

Galdikas. 1984. Adaptasi Orangutan Di Suaka Tanjung Puting Kalimantan Tengah. Universitas Indonesia. Jakarta.

Galdikas. 1986. Adaptasi Orangutan Di Suaka Tanjung Puting Kalimantan Tengah. Universitas Indonesia. Jakarta.

Groves, C.P. 1999. The Taxonomy of Orang-utans. In Orangutan Action Plan. Editor C. Yeager. DirJen PKA ; WWF-Indonesia ; CERC.

Maple, T.L. 1980. Orang-utan Behavior (Van Nostrand and Reinhold Primate Behavior and Development Series). Van Nostrand Reinhold Company. New York.

Marpaung. 1995. Tindak Pidana Terhadap Hutan, Hasil Hutan dan Satwa. Penerbit Erlangga. Jakarta.

Meijaard, E., H.D. Rijksen., S.N. Kartikasari. 2001. Di Ambang Kepunahan !, Kondisi Orangutan
Liar di Awal Abad ke-21. Penyunting S.N. Kartikasari. The Gibbon Foundation Indonesia. Jakarta.

Murzani, B. 2004. Studi Perilaku Makan Bekantan (Nasalis Larvatus, Wurmb) Di Kawasan Taman Wisata Alam Sungai Liku Kecamatan Paloh Kabupaten Sambas Kalimantan Barat. Skripsi Fakultas Kehutanan Universitas Tanjungpura. Pontianak.

Primack, R.B., J. Supriatna, M. Indrawan, P. Kramadibrata. 1998. Biologi Konservasi. Yayasan Obor Indonesia. Jakarta.

Rijksen, D.H. 1978. A Fieldstudy on Sumatran Orang Utans (Pongo pygmaeus abelii Lesson 1827) Ecology, Behavior and Conservation. Wageningen (NL) : Agricultural University.

Rowe, N. 1996. The Pictorial Guide to The Living Primates. Pogonias Press. East Hampton-New York.

Supriatna, J. dan E.H. Wahyono. 2000. Panduan Lapangan Primata Indonesia. Yayasan Obor Indonesia. Jakarta.

Whitten, J. and A. Compost. 1998. Tropical Wildlife of Southeast Asia. Periplus Edition. Singapura.

WWF Indonesia. 2011. Orangutan Borneo. Jakarta. 